\title{
AVALIAÇÃO DA EFICIÊNCIA ENERGÉTICA EM HABITAÇÃO DE INTERESSE SOCIAL
}

\author{
VIANA, Shaiane Gomes \\ Universidade de Fortaleza, e-mail: shaiane@edu.unifor.br \\ LEITE, Renan Cid Varela \\ Universidade Federal do Ceará, e-mail: renancid@bol.com.br \\ NAZARETH, Samuel Bertrand Melo \\ Universidade Presbiteriana Mackenzie, e-mail: bmnsamuel@gmail.com
}

\begin{abstract}
RESUMO
Sabendo que as opções para simular as variáveis do conforto ambiental são inúmeras, no presente trabalho foram utilizados programas computacionais para verificar o desempenho ambiental de uma unidade de habitação social, situada na cidade de Fortaleza. Entre as ferramentas computacionais, avaliou-se a eficiência das proteções solates utilizando o Autodesk Ecotect Analysis e seu plugin Radiance para verificação dos níveis de iluminação natural, o Autodesk Flowdesign para análise da ventilação natural e o Designbuilder para avaliação do conforto térmico em ambientes selecionados da unidade residencial. Nesta primeira experiência em graduação, todos esses softwares foram utilizados em conjunto a fim de tornar mais acessível e simplificado o processo de análise específica de conforto ambiental aos alunos da disciplina intitulada Tópicos Especiais de Conforto Ambiental. Os resultados obtidos através do uso destas ferramentas computacionais materializam em valores os benefícios das propostas de desenho consciente da edificação quanto aos aspectos ambientais, quantificando 0 impacto que esses elementos podem causar sobre o espaço construído.
\end{abstract}

Palavras-chave: Simulação computacional, Conforto ambiental, Desempenho térmico.

\begin{abstract}
Many options are available to simulate environmental comfort variables. In this present work several computer programs were applied to verify the environmental performance of a social housing in the city of Fortaleza. Among the computational tools, Autodesk Ecotect Analysis was applied to evaluate the efficiency of solar protections designed and its plugin Radiante was verify natural illumination levels, Autodesk Flowdesign to analyse natural ventilation and Designbuilder was used evaluate thermal comfort in selected rooms of the housing unit. In this first undergraduate experience, these softwares were used bodily with the objective of providing accessible, easy the specific analysis process of environmental comfort for the students of a theme named Special Topics in Environmental Comfort. The results obtained using these computational tools materialize the benefits of an environmental conscious design proposal, quantifying the impact of such elements over built spaces.
\end{abstract}

Keywords: Computer simulation, Ambiental confort, Thermal performance.

\section{INTRODUÇÃO}

Um dos aspectos fundamentais da arquitetura é proporcionar conforto aos ocupantes de ambientes internos. A ASHRAE (2004) define conforto térmico como a condição mental que expressa satisfação com o ambiente térmico.

VIANA, S.; BERTRAND, S; LEITE, R. Avaliação da eficiência energética em Habitação de Interesse Social. In: SIMPÓSIO BRASILEIRO DE QUALIDADE DO PROJETO NO AMBIENTE CONSTRUÍDO, 6., 2019, Uberlândia. Anais... Uberlândia: PPGAU/FAUeD/UFU, 2019. p. 1062-1073. DOI https://doi.org/10.14393/sbqp19097. 
Tal condição depende da interação de quatro fatores objetivos: a temperatura, a umidade e a velocidade do ar e a temperatura que irradiam as superfícies que encerram o ambiente. A adoção de limites de temperatura e umidade do ar, nos quais o corpo humano está em equilíbrio higrotérmico, delimita um intervalo denominado de zona de conforto.

O uso adequado dos recursos naturais é benéfico. Givoni (1962) acrescenta que a ventilação constitui a mais simples estratégia para a obtenção de conforto térmico, quando a temperatura interna é elevada. Bittencourt, Cruz e Lôbo (1997) reiteram que, o conjunto de estratégias de proteção solar com o uso passivo da ventilação natural, constitui a melhor relação custo benefício para o contexto de regiões quentes e úmidas. Zhao et al. (2011) comentam que o respeito às condições climáticas pode gerar aumento na saúde dos habitantes de uma cidade, promovendo conforto ambiental.

Programas de simulação computacional permitem modelar de forma detalhada a geometria da edificação, prever o impacto da radiação sobre aberturas, os níveis de iluminação natural, o comportamento do campo de vento no entorno e a pressão incidente em suas superfícies, incorporar características termofísicas dos materiais construtivos, definir as rotinas de ocupação, tipos de equipamentos e os sistemas para resfriamento e aquecimento utilizados, entre outros aspectos.

Esse artigo compreende a importância do desempenho ambiental como meta do projeto arquitetônico em virtude do seu impacto sobre o ambiente natural e os ocupantes de uma edificação. Nesse sentido, busca trazer a alunos de graduação em Arquitetura e Urbanismo, em disciplina especifica voltada ao tema, a experiência de utilização de diferentes ferramentas computacionais em sequência para analisar algumas das variáveis ambientais envolvidas, uma vez que o impacto das decisões projetuais é fundamental ao desempenho térmico, às condições de conforto e ao consumo de energia em edifícios.

Neste artigo, são resumidos os principais resultados obtidos com as ferramentas utilizadas para modelar uma edificação residencial de interesse social e avaliar o projeto em relação às condições de insolação das aberturas, o desempenho luminoso, a ventilação natural e o conforto térmico.

\section{OBJETIVO}

Avaliar o desempenho térmico de edificação de interesse social, através de simulação computacional em programas acessíveis a estudantes como ferramentas de previsão do comportamento ambiental de edificações, discutindo suas vantagens e dificuldades à incorporação ao processo de projeto.

\section{MÉTODO}

Para simular o conforto térmico na unidade residencial de interesse social, as ferramentas computacionais foram utilizadas segundo suas características específicas e dentro de suas capacidades. A seguinte sequência foi adotada: a modelagem inicial foi realizada no Skecthup a partir de uma base da edificação importada em .dxf. Em seguida, o Autodesk Ecotect Analysis 2011 para simular as condições de insolação da unidade e desenhar as proteções 
solares (brises) para uma segunda simulação e extração das máscaras de sombras. Com a ajuda do plugin Radiance para o Ecotect, foi realizada a simulação de luz natural fazendo-se necessário a quantidade de 300 lux por ambiente da unidade habitacional.

Para as simulações de ventilação, foi utilizado o software Flow Design, onde a mesma casa modelada no Sketchup foi salva em extensão .3ds inserida no túnel de vento virtual para definir o campo de pressões sobre as superfícies e negativas e positivas nas fachadas da edificação.

O valor da pressão foi necessário para o cálculo do coeficiente de pressão que compõe o cálculo da vazão do ar e resulta no número de renovação de ar por hora. A quantidade de renovação do ar faz-se necessário para inserir no próximo software, o DesignBuilder, que calcula e simula os dados georreferenciados, por hora, dia e ano de acordo com o ambiente da casa selecionado.

No caso dessa pesquisa, foram utilizados os ambientes de permanência prolongada: quartos e sala. Os dados de temperatura operativa e de ganhos de radiação são extraídos do DesignBuilder e levados para o ultimo software, o Excel, que, por meio de cálculos complementares, se torna possível descobrir graus horas desconforto, horas de conforto e desconforto e radiação das edificações com e sem a presença do brise, permitindo avaliar a melhoria que as proteções solares trazem para o conforto térmico.

\subsection{Características construtivas da edificação}

O software DesignBuilder, utilizado para realizar simulações de conforto térmico, limitou a especificação de alguns componentes da edificação, sendo possível especificar os materiais dos componentes base, que constituem a unidade habitacional. Desta forma, o sistema construtivo da edificação compõe-se basicamente pela laje de concreto com revestimento cerâmico, vedações externas e internas de alvenaria de tijolo cerâmico de 8 (oito) furos de $14 \mathrm{~cm}$, telhado de telha de barro sem forro, esquadrias com vidro single clear $3 \mathrm{~mm}$ e perfis de madeira assim como brises adicionados.

Para iluminação geral da unidade habitacional, foi criada uma rotina de uma suposta família tradicional brasileira que ocupa sua casa durante os dozes meses do ano e necessita da iluminação artificial de 6:00 (seis) ás 7:00 (sete) horas da manhã antes de ir ao trabalho e das 18:00 (dezoito) às 22 (vinte e duas) após regressar do trabalho até o momento de dormir. Foram criadas rotinas diferentes para as ocupação dos quartos e da sala: os quartos possuem ocupação das 21:00 (vinte e uma) horas até às 6:00 (seis) horas da manhã do dia seguinte e, no período da tarde, das 13:00 (treze) às 14 (quatorze) horas, suposto horário de almoço.

Na aba HVAC do DesignBuilder, foi possível inserir a quantidade de trocas de ar (44) calculado no item 3.3.4 desse artigo, assim como determinar que a única fonte de ventilação é a natural. Desta forma, tornou-se realizável as simulações necessárias para verificação e avaliação do conforto térmico da unidade habitacional em questão. 
Quadro 1 - Cálculos realizados

\begin{tabular}{|c|c|c|}
\hline \multicolumn{3}{|l|}{$\begin{array}{l}\text { Paredes (Valor de U) } \\
\begin{aligned} \text { Cálculo realizado } \\
\text { Resistência - Parede Vertical }=0,17 \\
\text { - Parede Horizon } \\
\text { - Parede Horizon }\end{aligned}\end{array}$} \\
\hline \multicolumn{3}{|l|}{ Resistência do Tijolo: } \\
\hline Seção 01 & Seç & ão 02 \\
\hline $\begin{array}{l}\mathbf{A} 1=0,01 \times 0,19 \\
\mathbf{A} 1=0,0019 \mathrm{~m}^{2}\end{array}$ & $\begin{array}{l}\text { A2 }=0,035 \times 0,1 \\
\text { A2 }=0,00665 \mathrm{~m}\end{array}$ & \\
\hline $\mathbf{R} \mathbf{1}=\frac{e \text { cerâmica }}{\lambda \text { cerâmica }}=\frac{0,09}{0,90}=0,1$ & $\begin{array}{r}\mathbf{R} 2=\frac{e \text { cerâmica }}{\lambda \text { cerâmica }} \\
\mathbf{R} 2= \\
\mathbf{R} 2=\end{array}$ & $\begin{array}{l}+\mathrm{RAR}+\frac{e \text { cerâmica }}{\lambda \text { cerầmica }}+\mathrm{RAR}+\frac{e \text { cerâmica }}{\lambda \text { cerâtmica }}+\mathrm{RAR} \\
\frac{0,01}{0,90}+0,16+\frac{0,01}{0,90}+16+\frac{0,01}{0,90}+16 \\
0,3533\end{array}$ \\
\hline \multicolumn{3}{|c|}{$\begin{aligned} & \text { RTIJOLO }= \frac{5 x A 1+4 x A 2}{\frac{5 x A 1}{R 1}+\frac{4 x A 2}{R 2}} \text { RTIJOLO }=\frac{5 x 0,0019+4 x 0,00665}{\frac{5 x 0,0019}{0,1}+\frac{4 x 0,00665}{0,35}} \\
& \text { RTIJOLO }=0,212\left(\mathbf{m}^{2} \mathbf{k}\right) / \mathbf{w}\end{aligned}$} \\
\hline \multicolumn{3}{|l|}{ Resistência da Parede (Argamassa): } \\
\hline Seção 03 & & Seção 04 \\
\hline $\begin{array}{l}\text { A3 }=0,01 \times 0,19 \\
\text { A3 }=0,0019 \mathrm{~m}^{2}\end{array}$ & & $\begin{array}{l}\mathbf{A} 4=0,19 \times 0,19 \\
\mathbf{A} 2=0,036 \mathrm{~m}^{2}\end{array}$ \\
\hline $\begin{array}{l}\mathbf{R 3}=\frac{e \text { reboco }}{\lambda \text { reboco }}+\frac{e \text { argamassa }}{\lambda \text { argamassa }}+\frac{e \text { reboco }}{\lambda \text { reboco }} \\
\mathbf{R 3}=\frac{0,02}{1,15}+\frac{0,09}{1,15}+\frac{0,02}{1,15} \\
\mathbf{R 3}=0,113\end{array}$ & & $\begin{array}{l}\mathbf{R} 4=\frac{\text { e reboco }}{\lambda \text { rehocn }}+\text { RTIJOLO }+\frac{\text { e reboco }}{\lambda \text { rehocn }} \\
\mathbf{R} 2=\frac{0,02}{1,15}+0,212+\frac{0,02}{1,15} \\
\mathbf{R} 2=0,2467\end{array}$ \\
\hline RPA & $\begin{aligned} \text { REDE } & =\frac{A 3+A 3}{\frac{A 3}{R R}+\frac{A 3}{R A}} \\
\text { REDE } & =0,2328 \\
\mathbf{U} & =\frac{\mathbf{1}}{\mathbf{0 , 4 0}}\end{aligned}$ & 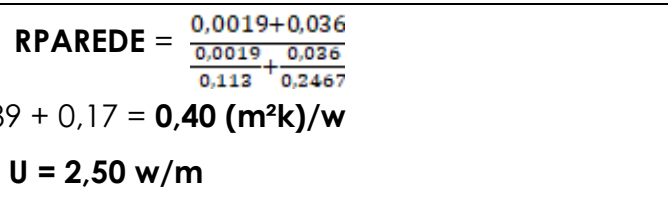 \\
\hline
\end{tabular}

Fonte: Elaborado pelos autores

A edificação está situada na cidade de Fortaleza, classificada na NBR 15.220 na zona bioclimática 8 .

\begin{tabular}{|c|c|c|}
\hline \multicolumn{3}{|c|}{ Transmitåncia Térmica U } \\
\hline \multicolumn{3}{|c|}{ W/m $\mathrm{m}^{2} \cdot \mathrm{K}$} \\
\hline Zonas 1 e 2 & \multicolumn{2}{|c|}{ Zonas $3,4,5,6,7$ e 8} \\
\hline \multirow[t]{2}{*}{$U \leq 2,5$} & $\alpha^{2} \leq 0.6$ & $\alpha^{*}>0,6$ \\
\hline & $U \leq 3,7$ & $U \leq 2,5$ \\
\hline$\alpha$ é absortâneia à radiaçăos & parede. & \\
\hline
\end{tabular}

Figura 1 - Transmitância térmica de paredes externas -

Fonte: NBR 15.575

O valor da resistência $U$ das paredes de tijolos de 8 furos e $14 \mathrm{~cm}$ da unidade residencial, tanto no cálculo demonstrado no item 5 desse relatório quanto pelo cálculo do software Design Builder, é menor ou igual ao valor de 2,5, como descrito na tabela. Isto posto, se enquadram na norma da NBR 15.575. 


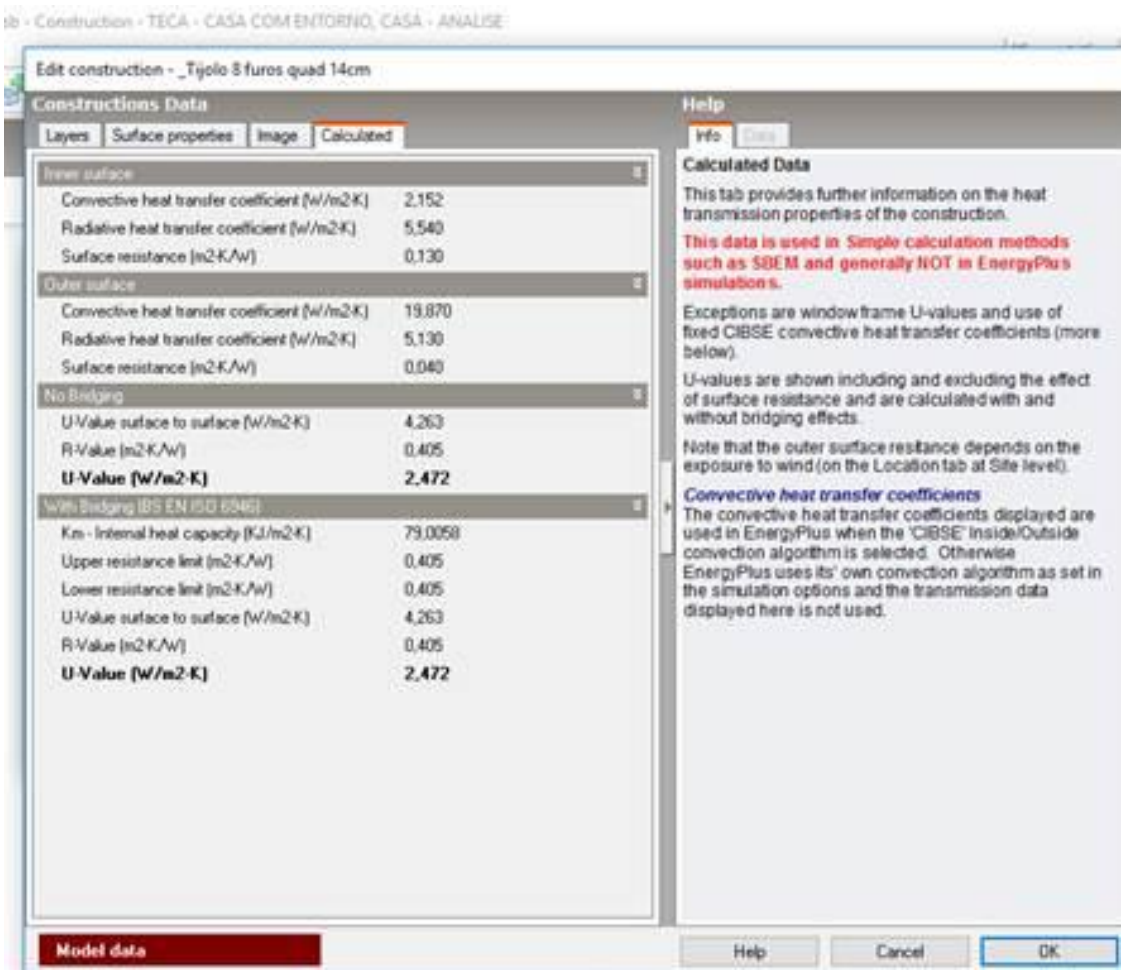

Figura 2 - Design builder: valor de U tijolo 8 furos $14 \mathrm{~cm}$ Fonte: Software Design builder, dados inseridos pelos autores

\section{ANÁLISE DE RESULTADOS}

\subsection{Avaliação das condições de insolação}

Uma unidade habitacional foi utilizada para simulações de insolação e de iluminação com e sem proteções solares (brises). Para as simulações de insolação, o software aplicado foi o Ecotect. Por meio dele, foram extraídas as cartas solares da edificação, e, ainda na mesma plataforma, apenas com a ajuda do pluginradiance, foram simulados dados de iluminação e extraídos para esse relatório.

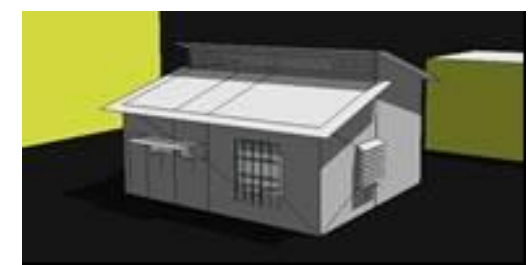

Solstício de verão - fachada oeste / sul

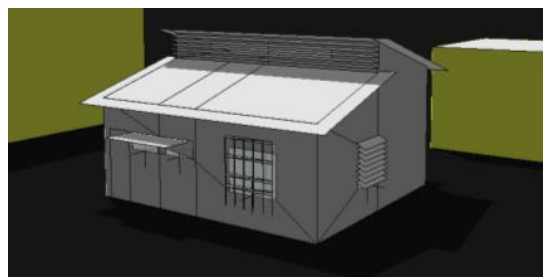

Solstício de inverno - fachada oeste / sul

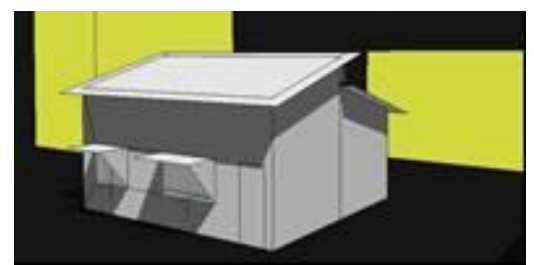

Solstício de verão - fachada leste / norte

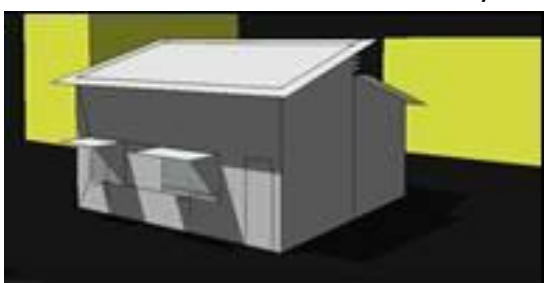

Solstício de inverno - fachada leste / norte

Figura 3 - Simulações de insolação -

Fonte: Software Ecotect, dados inseridos pelos autores 

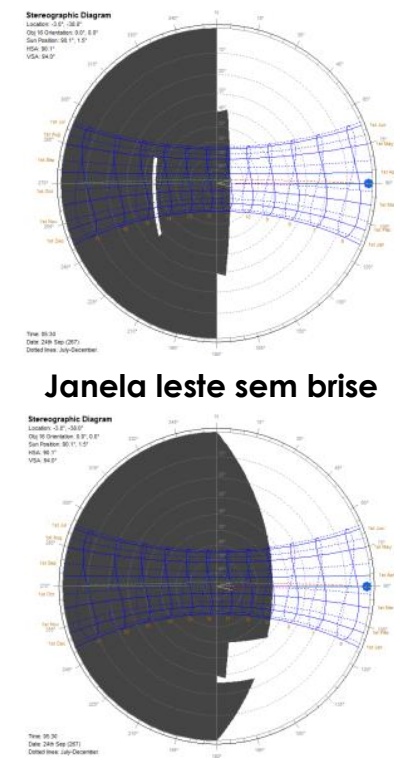

Janela leste com brise

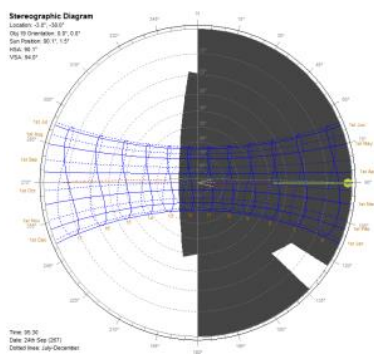

Janela oeste sem brise

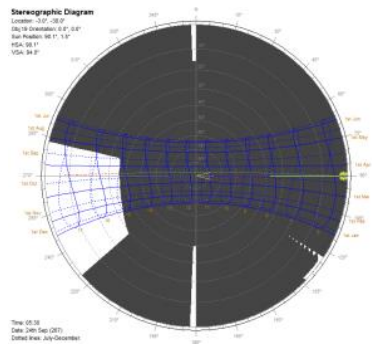

Janela oeste com brise

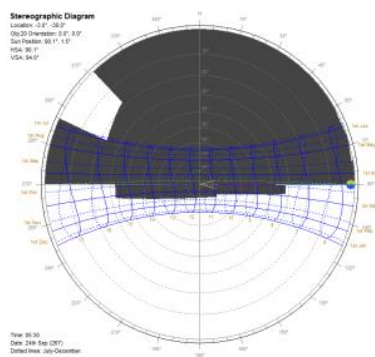

Janela sul sem brise

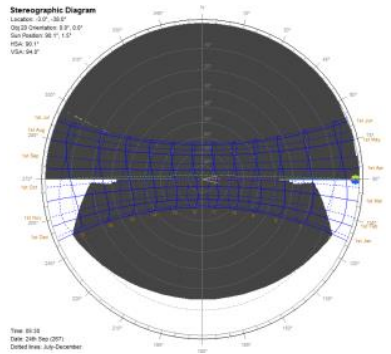

Janela sul com brise

Figura 4 - Simulações de máscaras de sombra com brise e sem brise -

Fonte: Software Ecotect, dados inseridos pelos autores

O Ecotect possui uma modelagem fácil e permitiu a verificação das máscaras de sombra das edificações sem brise e com brises de forma simples, rápida e georreferenciadas. Logo após o desenho de um simples brise em uma das fachadas, é possível verificar em Calculate/ sun-patch diagram a carta solar da fachada selecionada da edificação. De acordo com as máscaras, é possível perceber que os brises desenhados conseguem sombrear as fachadas das 9 da manhã às 16 horas da tarde.

\subsection{Avaliação das condições de iluminação natural}

O Radiance, um plugin do Ecotect, tornou possível a verificação da iluminação natural que incide no plano de trabalho que foi pré-determinado com altura de $80 \mathrm{~cm}$ (grid position em 800). Nesse plano, o objetivo de luminosidade era de, no mínimo, 300 lux, pois é o necessário para realização da atividade de leitura. Com base nas imagens, verificou-se que o menor valor apresentado foi no solstício de inverno com 299 lux. Dessa maneira, o objetivo do brise foi alcançado, pois o mesmo que protege também possibilita a passagem de iluminação necessária.

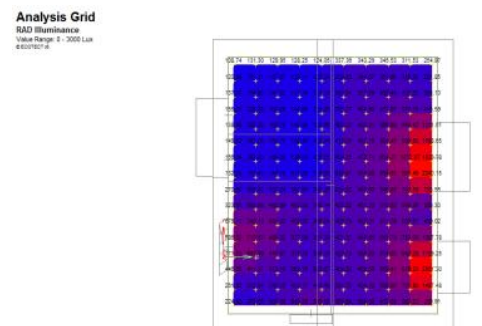

lluminação do solstício de verão 22 de dezembro- 09:00

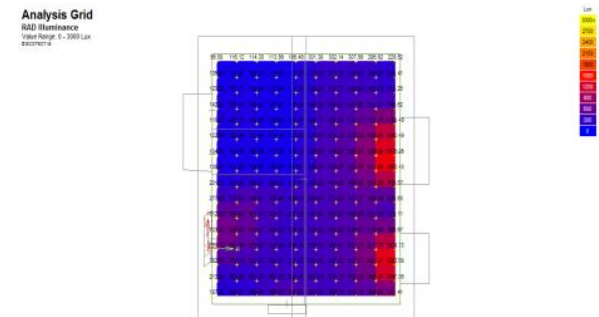

lluminação do solstício de inverno 22 de junho- 09:00

Figura 5 - Menor nível de iluminância do dia (com brises) -

Fonte: Plugin Radiance, dados inseridos pelos autores 


\subsection{Avaliação das condições de ventilação natural}

Ao passar por uma edificação, o vento gera um campo de velocidades e pressões em suas superfícies externas. Esse campo de pressões nas fachadas depende da direção e da intensidade do vento incidente, da densidade do ar, da forma e da orientação da superfície e características do entorno, tais como a topografia e a rugosidade do terreno.

Comumente a pressão é positiva a barlavento e negativa a sotavento. Ao criar zonas de alta e baixa pressão nas diferentes faces do edifício, o vento induz o movimento do ar no interior da edificação e esses fluxos dependem essencialmente dos coeficientes de pressão nas fachadas.

A determinação dos valores de $\mathrm{Cp}$ nas fachadas e na cobertura de edificações é fundamental para cálculos de taxas de infiltração de ar e ventilação natural.

Utilizou-se o programa Autodesk Flowdesign, de distribuição gratuita para usuários cadastrados no site da empresa, para avaliar as condições de ventilação natural no entorno e calcular os dados de coeficientes de pressão sobre as aberturas. Com base nesses dados, foi calculada a vazão de ar possível no ambiente da casa avaliada.

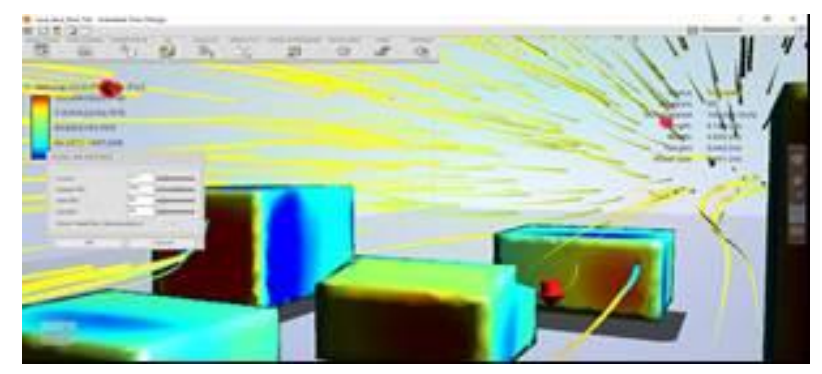

Figura 6 - Simulação flowdesign - pressões positivas e negativas Fonte: Software Flowdesign, dados inseridos pelos autores

Quadro 2 - Avaliação quantitativa - cálculo da vazão de ar - cálculo do coeficiente de pressão de cada janela

\begin{tabular}{|l|l|l|l|}
\hline \multicolumn{2}{|c|}{ JANELA LESTE SALA } & \multicolumn{1}{c|}{ JANELA LESTE QUARTO } \\
\hline Pressão (Pa) & 10 & Pressão (Pa) & 4 \\
\hline Velocidade (m/s) & 4,5 & Velocidade (m/s) & 4,5 \\
\hline Coeficiente de pressão (de entrada) & 0,806248 & $\begin{array}{l}\text { Coeficiente de pressão } \\
\text { (de entrada) }\end{array}$ & 0,322499 \\
\hline \multicolumn{2}{|c|}{ JANELA OESTE QUARTO JANELA OESTE QUARTO } \\
\hline Pressão (Pa) & -2 & Pressão (Pa) & -3 \\
\hline Velocidade (m/s) & 4,5 & Velocidade (m/s) & 4,5 \\
\hline Coeficiente de pressão (de saída) & $-0,16125$ & $\begin{array}{l}\text { Coeficiente de pressão } \\
\text { (de saída) }\end{array}$ & $-0,24187$ \\
\hline \multicolumn{1}{|c|}{ JANELA OESTE COZINHA JANELA OESTE WC } \\
\hline Pressão (Pa) & -3 & Pressão (Pa) & -3 \\
\hline Velocidade (m/s) & 4,5 & Velocidade (m/s) & 4,5 \\
\hline Coeficiente de pressão (de saída) & $-0,24187$ & $\begin{array}{l}\text { Coeficiente de pressão } \\
\text { (de saída) }\end{array}$ & $-0,24187$ \\
\hline
\end{tabular}


Quadro 3 - Avaliação quantitativa - cálculo da vazão de ar - Cálculo realizado: troca de ar por hora

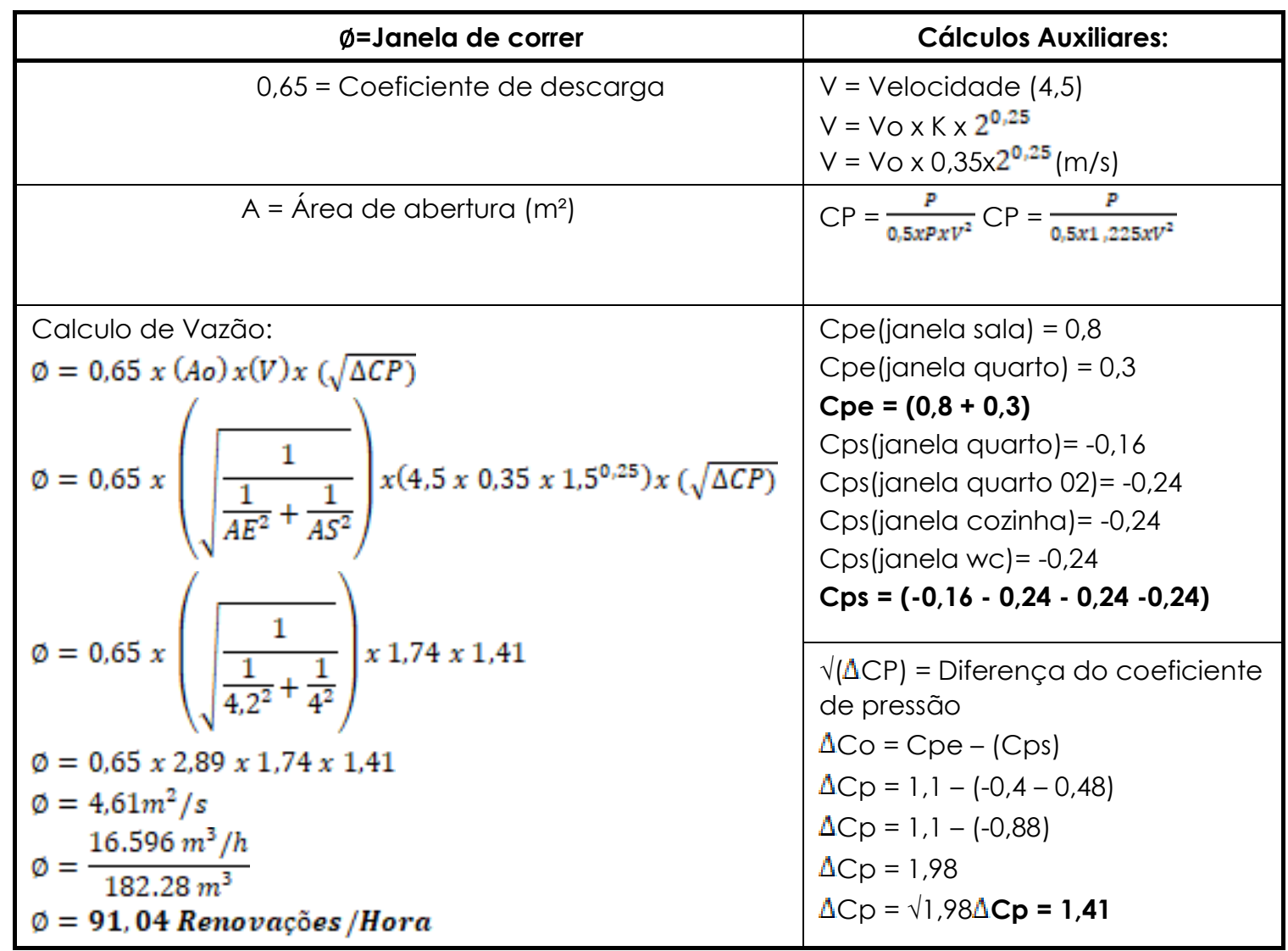

Fonte: Elaborado pelos autores

\subsection{Avaliação do desempenho térmico: Total de ganhos de calor devido à radiação solar}

O sol constitui a principal fonte de ganhos de calor em edifícios residenciais situados na região tropical. Nessas localidades, não é a temperatura do ar a principal causa de desconforto térmico, mas, sim, a temperatura radiante, resultado da incidência solar sobre as diversas superfícies que compõem o ambiente, aquecendo estas que, posteriormente, irradiam energia para 0 interior do edifício.

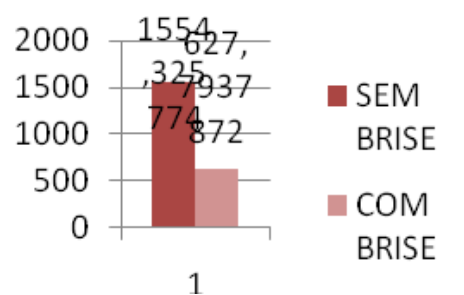

Quarto de casal

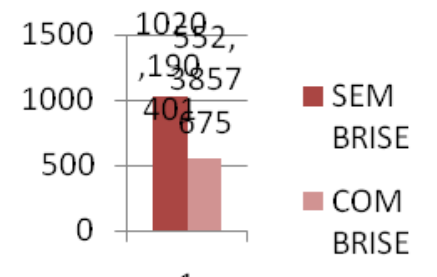

1

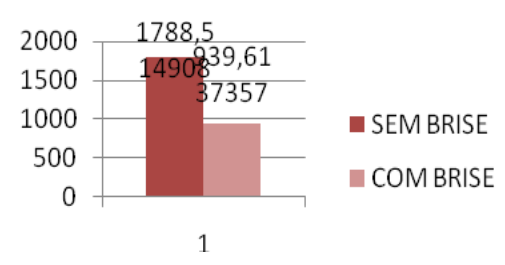

Sala

Figura 7 - Comparação dos ganhos de calor devido à radiação solar (sem e com brise) -

Fonte: Autores

A exposição à radiação solar deve, portanto, ser minimizada em climas quentes como maneira de reduzir a maior fonte de ganhos de calor e que é 
capaz de comprometer o conforto térmico no interior dos edifícios residenciais, elevando significativamente o consumo energético para resfriamento.

A verificação do total de ganhos de calor devido à radiação solar constitui, então, o parâmetro fundamental para análise das condições de conforto no ambiente interno de edificações.

O total anual é, aqui, comparado às situações com e sem elementos de proteção solar (Figura 7).

\subsection{Avaliação do conforto térmico}

Índices de conforto térmico têm sido empregados para diversos propósitos, desde a determinação de limites de exposição humana às condições do meio, passando pela definição de conforto térmico em ambientes residenciais e comerciais; ou a indicação da melhor estratégia para reestabelecimento das condições de conforto, até a classificação climática (AULICIEMS; SZOKOLAY, 2007).

Humphreys (1978) observou que o centro da zona de conforto poderia ser determinado a partir da temperatura ambiente mais frequentemente apontada como o confortável, determinando, assim, uma temperatura neutra.

A temperatura externa de referência é a única variável independente na equação para determinação da temperatura neutra utilizada nos modelos adaptativos. A temperatura média mensal foi o primeiro tipo de referência a ser utilizado. Uma vez que esse parâmetro baseia-se na série histórica de temperaturas do ar de um local específico, ele representa um clima típico e é, portanto, relacionado à experiência e aclimatação dos ocupantes (FERRARl; ZANOTTO, 2012). Givoni (1992) explica que ambientes de edifícios naturalmente ventilados acompanham as variações do clima devido a uma maior integração com este. Portanto, os usuários tendem a aceitar uma maior variação diária do que em edificações condicionadas artificialmente.

\subsubsection{Total de graus-hora de resfriamento (com brises $\mathrm{x}$ sem brises)}

O critério de avaliação indicado por RTQ - R (BRASIL, 2010) e o calculo dos graus-hora para resfriamento, sendo a temperatura base adotada e de $26^{\circ} \mathrm{C}$. Assim, após a realização da simulação, todas as horas com temperatura operativa acima de $26^{\circ} \mathrm{C}$ nos ambientes de permanência prolongada são somadas e, através da equação a seguir, é calculado o indicador de graushora para resfriamento.

$\mathrm{GH}_{\mathrm{R}}=\Sigma\left(\mathrm{T}_{\mathrm{O}}-26^{\circ} \mathrm{C}\right)$

Onde:

GHR = indicado de graus-hora para resfriamento

To $=$ temperatura operativa

O parâmetro "graus-hora" é determinado como a somatória da diferença da temperatura horária quando esta se encontra superior a temperatura de base, no caso de resfriamento, ou inferior à temperatura de base para graus-hora de aquecimento. Uma demonstração desse parâmetro é apresentada na figura a seguir, onde a área pintada em verde acima da linha de temperatura de $26^{\circ} \mathrm{C}$ representa a quantidade de graus-hora de resfriamento e a área pintada 
em vermelho, abaixo da linha de temperatura de $18^{\circ} \mathrm{C}$, representa a quantidade de graus-hora de aquecimento.

Os graus-hora geralmente são calculados para as temperaturas do ar. Porém, a quantidade de graus-hora, neste trabalho, será calculada para as temperaturas operativas.

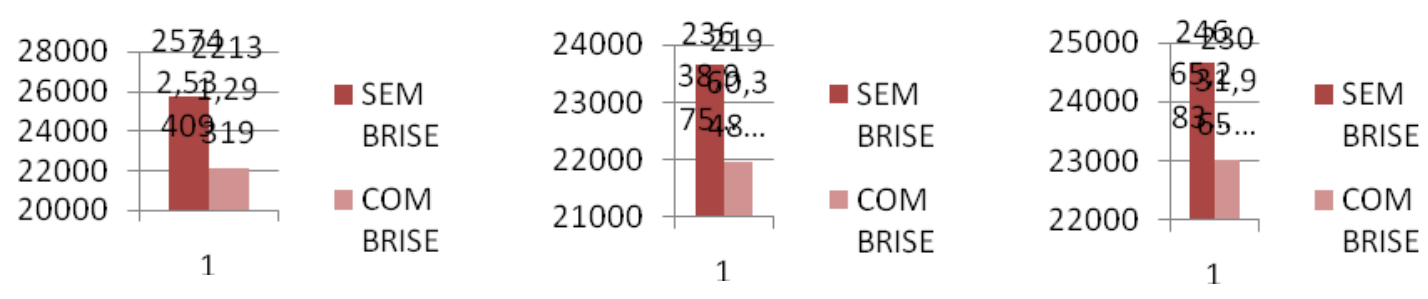

Quarto de casal

Quarto dos filhos

Sala

Figura 8 - Comparação dos graus horas de desconforto -

Fonte: Autores

\subsubsection{Total de horas em conforto - índice ASHRAE (2004)}

Durante a década de 1990, a ASHRAE direcionou um projeto de pesquisa específico que coletou dados de diferentes estudos de campo ao redor do mundo sobre conforto térmico (DEAR; BRAGER; COOPER, 1997). O resultado foi o projeto que culminou na revisão das normas até então vigentes.

Com base nas informações coletadas nessas pesquisas e utilizando a regressão linear, formulou-se a seguinte equação para prever a temperatura neutra (Tn) em função da temperatura externa (Te):

$\operatorname{Tn}=0,31 \times T_{-} e+17,8$

Onde:

Tn = temperatura neutra;

Te = temperatura média exterior do mês avaliado

A equação resultante deste estudo foi incorporada à última versão da norma ASHRAE 55 (2004) para avaliação de das condições térmicas em ambientes internos com as seguintes limitações:

- Para o intervalo de temperatura entre $10^{\circ} \mathrm{C}$ e $33,5^{\circ} \mathrm{C}$;

- No caso de edifícios onde os ocupantes podem operar diretamente aberturas;

- Para atividades com baixas taxas metabólicas (<1,3 MET).

Faixas de temperatura aceitáveis em edifícios naturalmente ventilados foram especificadas como $\pm 3,5$ para $80 \%$ do total e $\pm 2,5$ para $90 \%$ de aceitação geral.

O desempenho térmico de cada ambiente é avaliado em termos do total de horas dentro da zona de conforto segundo o índice de DeDear e Brager (1998), com limites definidos como 2,5 graus a mais e a menos da temperatura operativa

A temperatura operativa foi calculada como sendo o valor médio entre a temperatura do ar e a temperatura radiante média. 


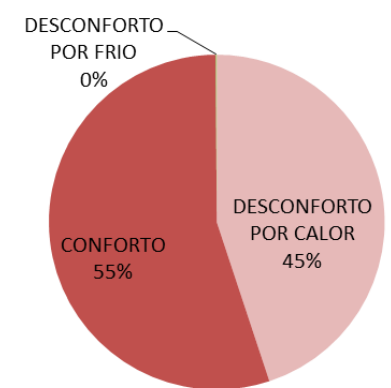

Quarto do casal, sem brise

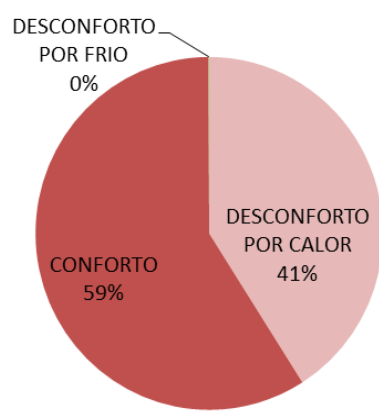

Quarto do casal, com brise

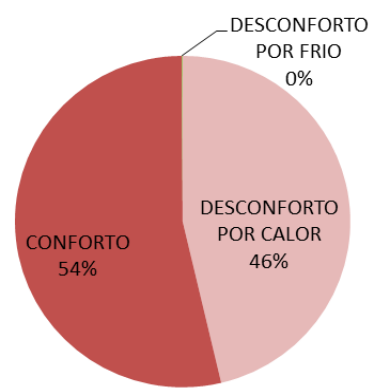

Quarto dos filhos, sem brise

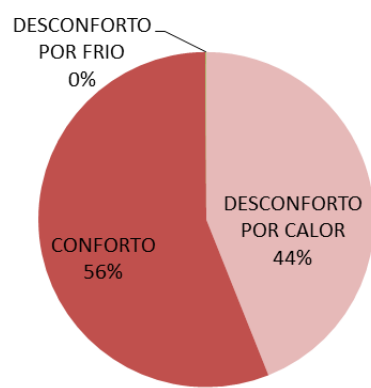

Quarto dos filhos, com brise

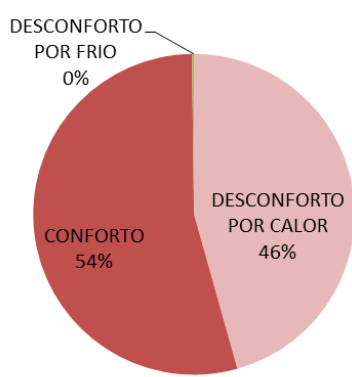

Sala, sem brise

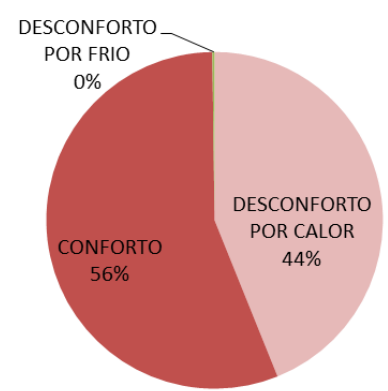

Sala, com brise

Figura 9 - Total de horas em conforto (sem e com brise) -

Fonte: Autores

O Design Builder necessita de uma modelagem na própria plataforma, pois ele não identifica bem as importações de outros softwares, ocasionando a demora do processo. Entretanto, o Design Builder, se bem configurado, gera ótimos resultados para avaliação do conforto térmico, como é possível observar nos gráficos acima em que ele simula os dados e as diferenças entre as modelagens, em que uma casa com brises pode apresentar um maior conforto naturalmente do que uma com a ausência dessa proteção.

\section{CONSIDERAÇÕES FINAIS}

O fato de se trabalhar com vários softwares para realização de um objetivo final, no caso o conforto térmico, é bastante desafiador, pois, por mais semelhantes que sejam, as plataformas e comandos são diferentes e é necessário um tempo de adaptação de uma ferramenta para outra. Quanto à trabalhabilidade das ferramentas, O SketchUp, O Ecotect e o seu pluginradiance e FlowDesing, são os mais simples de se utilizar e podem facilmente ser exportados de um para o outro sem grandes problemas. $O$ Design Builder é o que menos se integra aos outros, pois, para se fazer as simulações, é necessário modelar no próprio programa computacional. Ele não aceita bem a inserção de arquivos bases de outros softwares e seu campo de trabalho é mais complexo, sendo mais trabalhoso para realização da modelagem.

Em relação à clareza das informações, o Flow Design é o que deixa mais a desejar. Apesar de apresentar um visual simples, as informações sobre a pressão do vento não são tão fáceis de serem decodificadas e acabam sendo supostas numa escala que pode vir a variar significativamente. Sobre o comportamento térmico, as ferramentas apresentam as variáveis exemplares para softwares de avaliação de desempenho, principalmente o Design Builder 
e o Ecotect. Ambos possuem informações e dados simulados por georreferenciamento, o que torna seus resultados bem mais completos.

De acordo com resultados obtidos pelos programas computacionais, nos gráficos, é possível perceber que a unidade residencial de interesse social em questão, que possuí as proteções solares, consegue reduzir de $2 \%$ a $4 \%$ o desconforto por calor anualmente e diminui de 1 a 3 graus-hora anualmente de uma edificação que não possui os brises. Tais resultados não são práticos de serem extraídos, mas são valiosos para uma análise especifica de conforto ambiental, sendo importantes para o projeto da edificação quanto à verificação da necessidade das proteções e ganho a curto e longo prazo nas edificações. Desta maneira, os resultados difundem soluções positivas no uso de ferramentas computacionais para simulações de desempenho ambiental de uma edificação.

\section{REFERÊNCIAS}

ASSOCIAÇÃO BRASILEIRA DE NORMAS TÉCNICAS (ABNT). NBR 15220 - $\mathbf{3}$ : desempenho térmico de edificações residenciais. Parte 3 Zoneamentobioclimático brasileiro e diretrizes construtivas para habitações unifamiliares de interesse social. Rio de Janeiro, ABNT, 2005.

NBR 15575: desempenho de edifícios residenciais até cinco pavimentos. Rio de Janeiro, ABNT, 2013.

AULICIEMS, A.; SZOKOLAY, S. Thermalcomfort. PLEA Note 3. PLEA International/ University of Queensland. 2 ed. 2007.

BITTENCOURT, L. S.; CRUZ, M. J.; LÔBO, D. G. F. A influência da relação entre taxa de ocupação $\times n^{\circ}$ de pavimentos no potencial de ventilação natural dos ambientes internos e externos. In: ENCONTRO NACIONAL DE CONFORTO NO AMBIENTE CONSTRUÍDO, 4, ENCONTRO LATINO- AMERICANO DE CONFORTO NO AMBIENTE CONSTRUÍDO, 1997, Salvador. Anais... Salvador: ANTAC, 1997.

BRASIL. Regulamento Técnico da Qualidade para o nível de eficiência energética de Edificações Residenciais - RTQ-R. INMETRO - Instituto Nacional de Metrologia, Rio de Janeiro, 2012.

DEAR, R. J., BRAGER, G. S.; COOPER, D. ASHRAE RP-884 Final Report: developing an adaptive model of thermal comfort and preference. Atlanta: American Society of Heating, Refrigerating and Air-Conditioning Engineers; 1997.

FERRARI, S.; ZANOTTO, V. Adaptive comfort: Analysis and application of the main indices. Building and Environment, 49: 25-32, 2012.

GIVONI, B. Basic study of ventilation problems in houses in hot countries. Israel: Building Research Station of the Institute of Technology, 1962.

Comfort, climate analysis and building design guidelines. Energy and Buildings, 18, 1992.

ZHAO, C.; FU G.; LIU, X; FU, F. Urban Planning indicators, morphology and climate indicators; A case Study of north-south transect of Beijing, China. Building and Environment, n. 46, p. $1174-1183,2011$. 